\title{
The effect of activity deprivation upon subsequent activity
}

HENRY E. MARKS, RICHARD L. NARVER AND CECIL C. BRIDGES

TEXAS CHRISTIAN UNIVERSITY

Eighty naive, male rats were trained on activity whecis and then randomly placed in one of 16 groups formed on the basis of days of activity deprivation $(1,2,4$, and 8) and activity deprivation cage (ADC) sizes of 25-, 50-, 100-, and $200 \mathrm{sq}$. in. After removal from the ADC, the rats were tested in the activity wheels. An increase in cage size produced a negatively accelerated activity curve, reaching asymptote at the 100 in. cage size. The effects for days were unclear, probably as a result of the complexity of the interaction. Additional investigation of the phenomena is being undertaken.

Montgomery (1953) noted that eight days of activity deprivation had no effect on subsequent activity wheel behavior. Montgomery \& Zimbardo (1957) stated that 25,50 , and 100 days of activity deprivation, as well as three different cage sizes, produced no differences in maze activity. However, Hill (1956) has shown that short periods $(5,24,46-1 / 2 \mathrm{hr}$.) of activity deprivation produced significant subsequent increases in activity wheel behavior.

This experiment was designed to offer some additional data to help clarify the problem raised by these previous experiments: what is the relationship between duration of confinement and confinement cage size on subsequent activity? Since Hill found increases in activity for short periods of deprivation, while Montgomery found no differences for longer periods, it was decided to use deprivation periods of $1,2,4$, and 8 days. The activity wheel was used as a measure of activity since Strong (1957) has shown that it is one of the most sensitive measures of gross locomotor activity, and it was this type of activity which was being restricted. Method

Eighty naive, male rats of the Sprague-Dawley strain were used. All were approximately 55 days old at the start of the experiment. Two Wahmann activity wheels with automatic counters were used for all activity measures. Lacey's (1944) activity wheel calibration method was used to assure equivalence between the two wheels. Eighty individual, pine cages with $1 / 4$ in. hardware cloth tops were used as activity deprivation cages (ADC). The ADC sizes were (A) 25 sq.in., (B) 50 sq.in., (C) 100 sq.in., and (D) 200 sq.in. (floor area). All $A D C$ were 8 in. high and 5 in. wide, differing only in the dimension of length. There were $20 \mathrm{ADC}$ of each size.

The rats were housed in group cages (eight per cage) in the main colony until they were placed in the $A D C$. The ADC were located on tables (covered with
San-I-Cel, animal bedding on top of polyethylene film) in a quiet room. The overhead lights remained on and food and water was always available during the course of the experiment.

For the first five days all animals were given a $5 \mathrm{~min}$. session each day in the activity wheels to accustom them to the apparatus and to provide the covariate for the analysis of covariance. At the end of the fifth session animals were randomly assigned to groups and housed in the ADC. The 16 groups used in the experiment were formed for a 4 by 4 factorial design: I-A designating one day of deprivation in ADC size A, while IV-D designates eight days of activity deprivation in $A D C$ size $D$. On the sixth day, the first group (I-A, I-B, I-C, I-D) was removed from the ADC and immediately given a $10 \mathrm{~min}$. test in the activity wheels. The second group (II-A, II-B, etc.) was tested in the same manner on the seventh day; the third group was tested on the ninth day and the fourth group on the thirteenth day. All rats were tested at the same time of

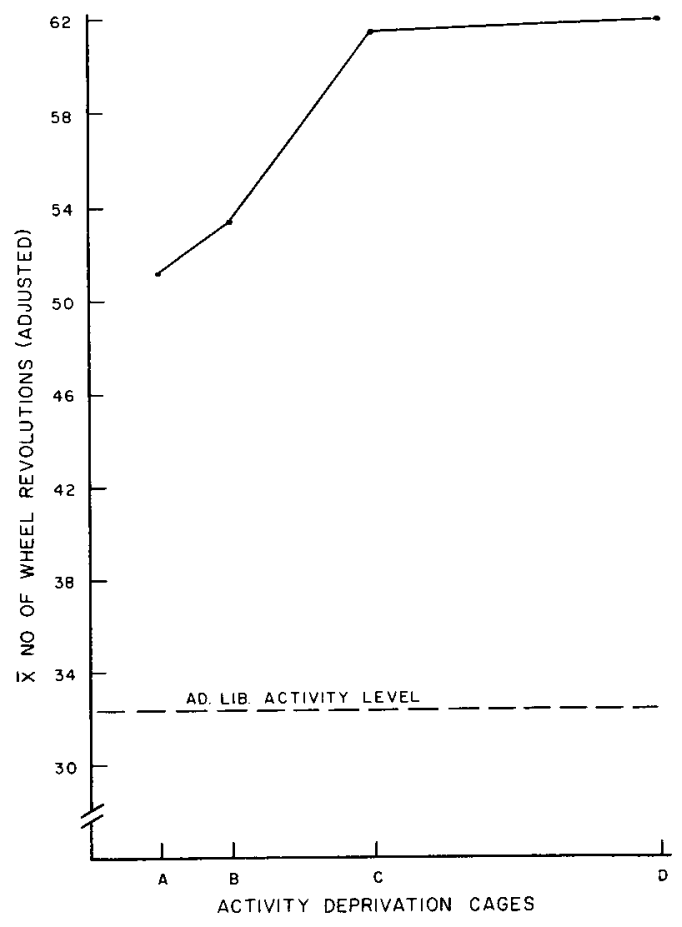

Fig. 1. Activity level as a function of activity deprivation cage size. 
day and no two rats of the same group were ever tested more than $90 \mathrm{~min}$. apart in order to reduce activity variations due to the diurnal activity cycle.

\section{Results and Discussion}

An analysis of covariance was performed. Duration of deprivation ( $F=13.67, \mathrm{df}=3 / 44, \mathrm{p}=.001$ ), ADC size $(\mathrm{F}=13.99, \mathrm{df}=3 / 44, \mathrm{p}=.001)$ and their interaction $(F=5.87, d f=9 / 44, p=.005)$ all have pronounced effects on subsequent activity wheel behavior. From Fig. 1, one can see that cage size has a direct relationship to subsequent activity up to an asymptotic point. Days of activity deprivation (Fig. 2) does not seem to show any such direct relationship. While Hill's results may be considered supported and Montgomery's subject to question, of greater concern is the problem of accounting for the decline in activity from day 2 to 4 and the subsequent increase from day 4 to 8 . However, this problem is further confounded when one plots days of deprivation separated into their various $A D C$ components (Fig. 3). From the statistical results, one can see that there is a significant interaction between

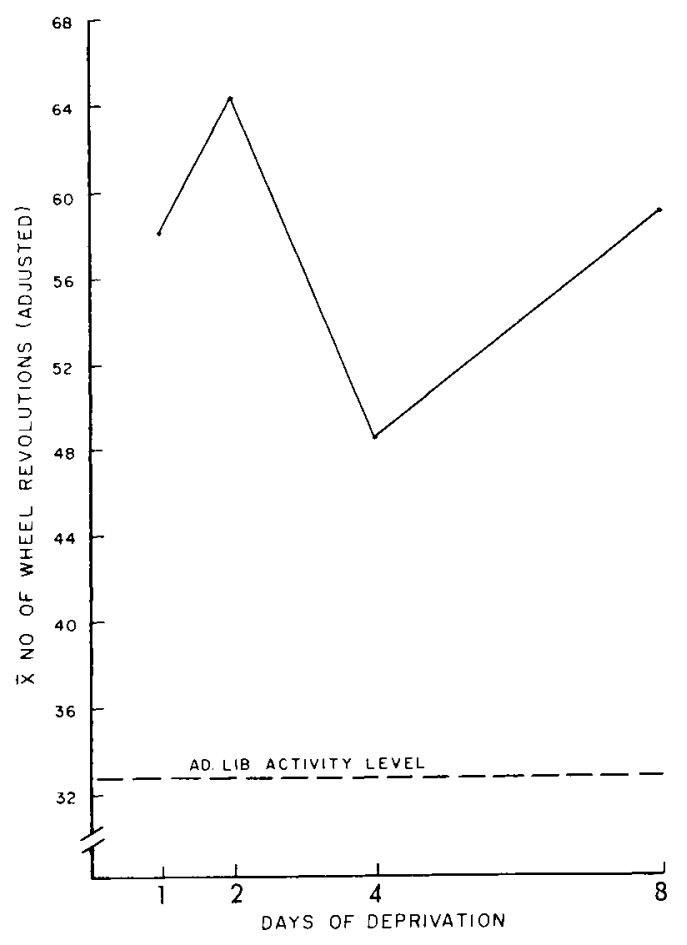

Fig. 2. Activity level as a function of days of activity deprivation.

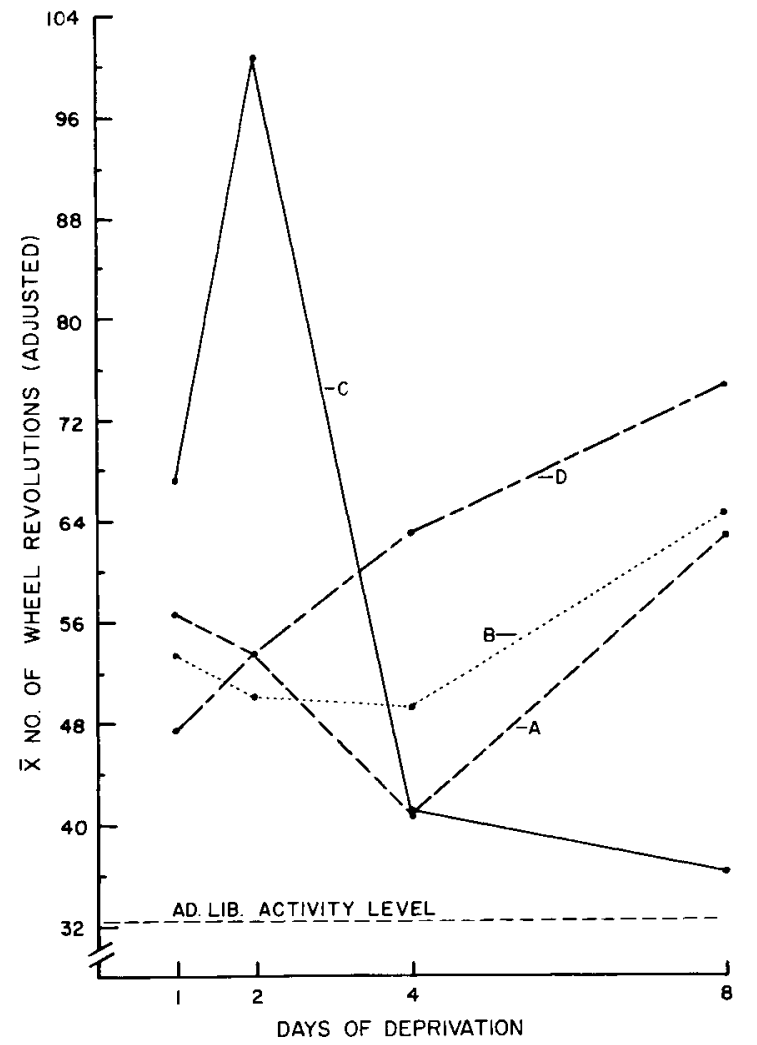

Fig. 3. Activity level as a function of days of activity deprivation separated into the respective ADC components.

ADC size and duration of deprivation, but the complexity of these individual results makes the relationship between them obscure. Additional experimentation is required before any firm theoretical statements can be made. The first author is presently engaged in designing several additional partial replications and enlarged, one-factor tests of this phenomenon.

\section{References}

Hill, W. F. Activity as an autonomous drive. J. comp. physiol. Psychol., 1956, 49, 15-19.

Lacey, $\mathbf{0}$. L. A revised procedure for the calibration of the activity wheel. Amer. J. Psychol., 1944, 57, 412-420.

Montgomery, K. C. The effect of activity deprivation on exploratory behavior. J. comp. physiol. Psychol., 1953, 46, 438-441.

Montgomery, K. C., \& Zimbardo, P. G. Effect of sensory and behavioral deprivation upon exploratory behavior in the tat. Percept. mot. Skills, 1957, 7, 223-224.

Strong, P. N. Activity in the rat as a function of apparatus and hunger. J. comp. physiol. Psychol., 1957, 50, 596-600. 